\title{
The use of nanomodified concrete in construction of high-rise buildings
}

\author{
Sergei Prokhorov ${ }^{1 *}$ \\ ${ }^{1}$ Vladimir State University named after A. and G. Stoletovs, Gorkiy street, 87, Vladimir, 600000, Russia
}

\begin{abstract}
Construction is one of the leading economy sectors. Currently, concrete is the basis of most of the structural elements, without which it is impossible to imagine the construction of a single building or facility. Their strength, reinforcement and the period of concrete lifetime are determined at the design stage,taking into account long-term operation. However, in real life, the number of impacts that affects the structural strength is pretty high. In some cases, they are random and do not have standardized values. This is especially true in the construction and exploitation of high-rise buildings and structures. Unlike the multi-storey buildings, they experience significant loads already at the stage of erection, as they support load-lifting mechanisms, formwork systems, workers, etc. The purpose of the presented article is to develop a methodology for estimating the internal fatigue of concrete structures based on changes in their electrical conductivity.
\end{abstract}

\section{Introduction}

The main requirements for reinforced concrete structures during construction and operation period are strength and resilience. [1]. When the concreting works, hardening rate of concrete and its real bearing capacity can be determined by various methods, including nondestructive. However, it is well known that the physical and mechanical properties of building structures changes under the action of various atmospheric, climatic, technological, human and other factors. Nondestructive testing methods are most often used to assess these changes and determine the actual strength $[2,3,4]$

However, these techniques have a number of disadvantages:

1. Inability of constant control over the state of structures.

Many constructions are based in inaccessible places or hidden under the finish coatings, which significantly complicates the assessment of their technical condition and makes it impossible to use the equipment;

2. Lack of opportunity to track changes in the fatigue state and the integrity of the structures at the micro level. In high-rise buildings high-strength concrete and steel are applied, however it should be noted that an increase in the strength of concrete increases its fragility and reduces its plastic-deformation properties, which entails an almost instantaneous destruction of the material when it reaches the limit state. [5,6] Therefore, the problem of determining (revealing) critical fatigue at an early stage is very acute.

\footnotetext{
* Corresponding author: oc204@bk.ru
} 
3. Some of the methods requires special preparation of the surface;

4. Methods have a local character of strength determination. [7]

The engineering systems of high-rise buildings widely use remote control of equipment and its condition, based on the collection and transfer of information to the dispatch center. This allows to diagnose malfunctions at an early stage and enables the use of preventive measures or let to prepare for the repair more carefully. [8,9]

The determination of internal fatigue according to the change in electrical resistivity of concrete, can become an alternative to existing methods.

Attempts to determine the internal fatigue in the concrete on the basis of changes in conductivity have been made long time ago. Adding modifying additives which fill the voids at the molecular level and turn the concrete from, practically, the dielectric into an electroconductive structure.[10,11] Among the most available, there can be distinguished method based on the determination of the electrical conductivity according to the transmission of electric current through the body of the structure, via electrodes located on one side of the structure. $[12,13]$ When using this method it's rather difficult to make an adequate estimate of the structure's state, due to the low convergence of the results. Furthermore it was found that the electrical resistance is strongly dependent on the water saturation of concrete, and as a result of current transmission, polarization of free ions occur, which leads to a distortion of results.

Another method of investigating the stress-strain state of concrete is tomography of electrical resistance, when 2 or $4 \mathrm{w}$ electrodes through which voltage is applied connected to the sample, and fix changes in electrical resistance under load. The method is based on measurement of the internal fields due to the piezoresistance effect. [14,15]

\section{Materials and methods}

The researches made on the base on Vladimir State University showed that the results of the change in the electrical conductivity of concrete samples depend on the concentration of the modifier (carbon pipes), electrode material, their configuration (there were investigated plate, perforated, mesh electrodes), and the depth of immersion.

Tests of fine-grained concrete were conducted on samples of cubes with edge size of 7 $\mathrm{cm}$ and beams with dimensions $4 \times 4 \times 16 \mathrm{~cm}$ in accordance with GOST $10180-2013$. Portland cement PC-TO-500-H manufactured by JSC "Mordovcement" was used as binder, and Quarry quartz sand was used as fine aggregate for obtaining samples. To prepare the mixture, distilled water was used in accordance with GOST 6709-72 in the volume of watercement ratio 0.5.Multilayered carbon nanotubes were used as a nano-modifying additive. Except increasing the strength of elements, the use of nano additives makes it possible to increase the electrical conductivity of concrete and to use it for internal fatigue estimation. At the stage of preparing carbon tubes $2 \mathrm{mkn}$ size are added to the a concrete. The preparation of the dispersion was carried out on a SONOPULS HD 3200 unit by ultrasonic treatment with a flat titanium probe TT 13, $13 \mathrm{~mm}$ in diameter. The treatment was carried out for 5-30 minutes at amplitude values of 10,50 and 100\%. The process was carried out in a glass beaker with constant cooling.

The temperature of the treated dispersion was controlled by means of a thermocouple entering.To uniformly distribute the nanomodified additives in the suspension, polycarboxylate hyper-plasticizer P-11 was used in the amount of $0.25 \%$ of the cement mass.

At the first stage of the research there were conducted experiments to select the qualitative and quantitative composition of the concrete mixture. The fine-grained concrete with a watercement ratio of 0.6 based on portland cement M 500 served as a standard. Samples were prepared with a percentage of carbon pipes $2 \mathrm{mkn}$ in length $0.01-0.13 \%$ by weight of cement. 
During the experiment, the strength of the samples and the electrical resistance at the age of $1,3,7,14$ and 28 days were determined.

The next step was to analyze the change in the electrical conductivity of concrete samples, depending on the material and method of the electrodes installation.

Three types of electrodes were tested:

lamellar solid (1 type)

grid with cells $0.5 \times 0.5 \mathrm{~mm}$ ( 2 type $)$

perforated with a cell size of $2 \times 2 \mathrm{~mm}$ (type 3 )

Before installation, the electrodes were stripped and embedded in the samples at the manufacturing stage.Indications were taken before the tests and during the loading to failure.The results were recorded with help of multimeter Mastech MS8040 and video fixation (Fig.1)Compression and bending tests was carried out on a hydraulic press BM-3,5.
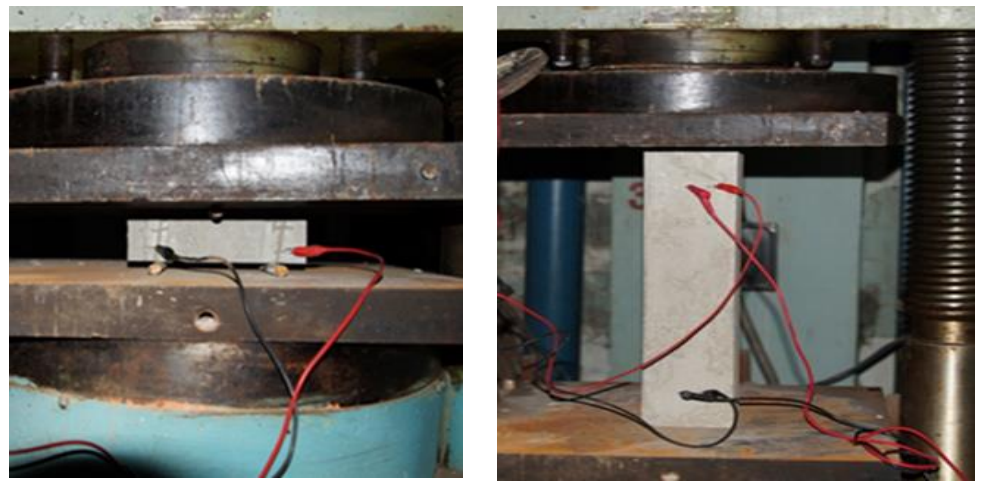

Fig. 1. Testing of samples

\section{Results}

The results of the effect of the percentage of nano modifying additive on strength and electrical resistance, which were produced during the research, are given in Table 1.

Table 1. The change in the strength characteristics and electrical resistivity of concrete, depending on the content of the nano modifying additive

\begin{tabular}{|c|c|c|c|c|c|c|}
\hline \multirow{3}{*}{$\begin{array}{l}\text { Content of nano } \\
\text { modifying } \\
\text { additive, } \%\end{array}$} & \multicolumn{6}{|c|}{ Storage duration } \\
\hline & \multicolumn{2}{|c|}{ 1day } & \multicolumn{2}{|c|}{ day 14} & \multicolumn{2}{|c|}{28 days } \\
\hline & $\begin{array}{l}\mathrm{Rc}, \\
\mathrm{MPa}\end{array}$ & $\mathrm{R}, \mathrm{MOhm}$ & $\begin{array}{l}\text { Rc, } \\
\text { MPa }\end{array}$ & $\mathrm{R}, \mathrm{MOhm}$ & $\begin{array}{l}\text { Rc, } \\
\mathrm{MPa}\end{array}$ & $\mathrm{R}, \mathrm{MOhm}$ \\
\hline 0 (reference) & 22 & 1,5 & 49 & 4,5 & 55 & 7,3 \\
\hline 0.01 & 26 & 1,5 & 65 & 4,5 & 73 & 7,1 \\
\hline 0.02 & 38 & 1,5 & 68 & 4,3 & 76 & 7,1 \\
\hline 0.03 & 31 & 1,3 & 71 & 4,3 & 77 & 7 \\
\hline 0.05 & 33 & 1,2 & 72 & 4,2 & 79 & 6,8 \\
\hline 0.07 & 34 & 1,2 & 73 & 4,0 & 82 & 6,7 \\
\hline 0.10 & 36 & 1,1 & 78 & 3,8 & 88 & 6,5 \\
\hline 0.13 & 38 & 1,1 & 71 & 3,8 & 76 & 6,5 \\
\hline
\end{tabular}


As can be seen from the table adding of carbon tubes not only improves the strength of concrete, but also increases its conductivity. This is explained by the creation of a more accurate pore size distribution and replacement of voids by nanomodified additives, which leads to a decrease in the resistivity. However, it should be noted that by increasing the concentration above $0.1 \%$ we get the decrease in strength of laboratory samples. Subsequently, tests were performed on all samples with a content of $0.1 \%$ carbon nanotubes by weight of cement.

Investigations of the effect of materials and electrode types on the electrical resistivity of concrete were carried out under a load of compression and bending.

The dependence of the change in the electrical resistivity of the control sample during bending is shown in Fig. 2.

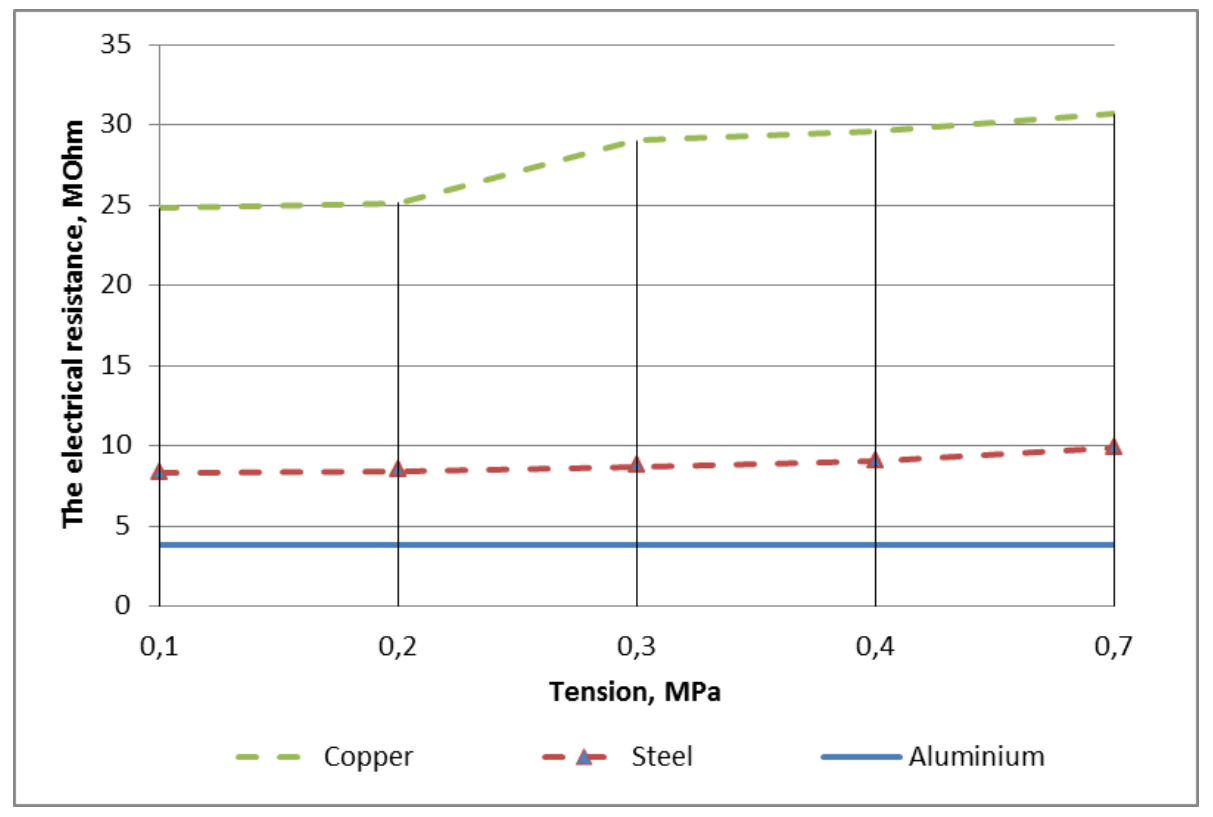

Fig. 2. The dependence of the change in the electrical resistivity of the control sample during bending

As can be seen from the graph (Fig. 2), the greatest change in electrical conductivity occurs on electrodes of type 3 , when bending. This is connected to the smaller specific surface area of the electrode located in the compressed zone, and when the microcracks appear, the electrical resistivity begins to increase. At the same time, when using the electrodes of type 2 , the change in electrical resistivity is insignificant due to better integration into the body of the sample, whereby the electrode moves together with the concrete without breaking the circuit.

In the graph of conductivity analysis using solid electrodes (type 1), it can be noted that the increase in electrical resistance occurs at voltages close to the limit. This is due to loss of a contact interface between the concrete and electrode, and the appearance of microcracks in the contact zone.

During the compression test of the sample, the overall picture of changes in the electrical conductivity is retained, but it takes a distinct character (Figure 3). 


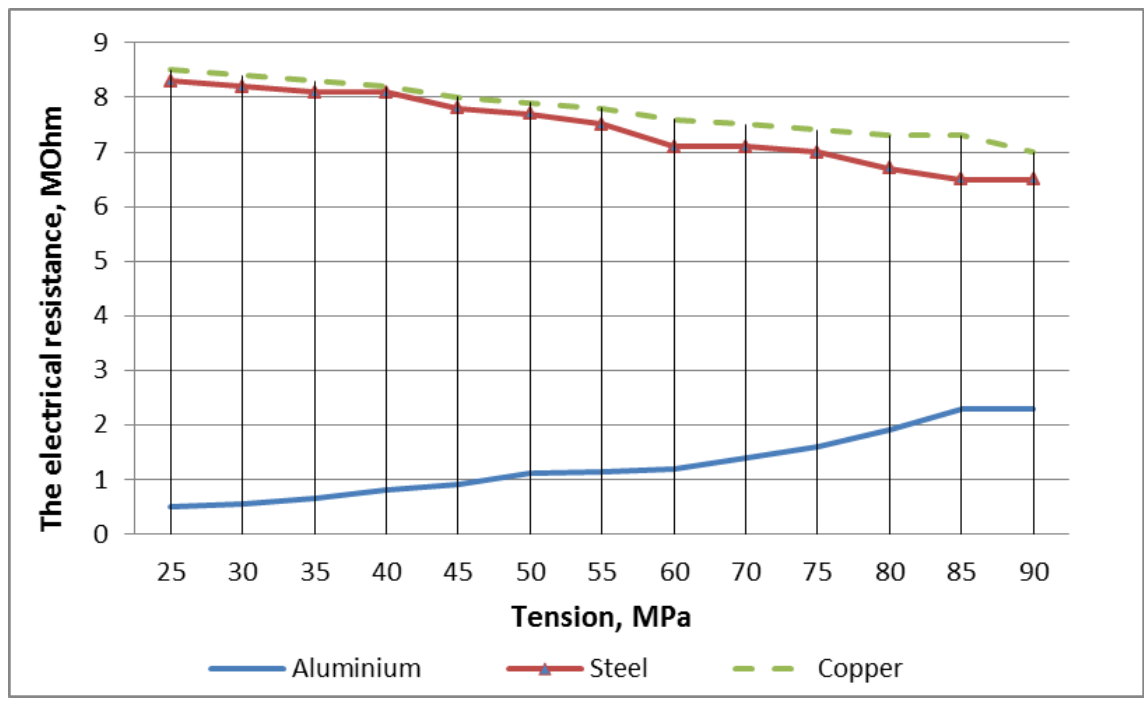

Fig. 3. Dependence of the change in the electrical resistivity of a control sample during compression.

In particular, type 1 and type 3 electrodes behave almost identically, as when microcracks appear in the compression zone, they quickly lose contact with the concrete, which leads to a sharp increase in the electrical resistivity. Electrodes of the second type show a smooth increase in electrical resistance, depending on the load, due to more deep integration into the body of the sample. In this case, the initial resistance is less than the resistance at destruction in 4 times, and for electrodes of the second type in 5 times.

The results showed that the specific resistance of concrete depends significantly on the resistance of the contact itself and the density of its adhesion to concrete.

If there is a gap between the electrode and the concrete, the contact area decreases and the resistance increases. Furthermore, there is a polarization of ions around the electrode, which entails a concrete polarization. This leads to an underestimation of the actual value.

When analyzing the change in the total electrical conductivity, depending on the period of concrete hardening, it can be noted that it decreases in the range of $40-150 \%$. This is explained by the contraction of free ions in the pores of $\mathrm{K}+, \mathrm{Na}+, \mathrm{O}-$ and less in $\mathrm{Ca} 2+$ and $\mathrm{SO} 2$.

When testing samples by cyclic loading, nano modified concrete shows the repeatability of electrical resistance values, while ordinary concrete has a significant spread after the load is removed (partially or fully), followed by loading again.

\section{Discussions}

In general, the researches have shown that the introduction of nano additives into concrete makes it possible to study the change in the stress-strain state of structures on the basis of electrical resistivity, more fully. During the hardening, microvoids in cement stone are filled with carbon pipes, which leads to an increase in strength by $10 \%$ on one hand, and on the other, to the formation of stable bonds for the passage of electric current along the body of the structure. The change in electrical resistance occurs more evenly.

The obtained results allow us to define the internal voltage in the sample with an accuracy of $10-15 \%$. The work on the adjustment of the composition of the concrete mix and the development of software for the interpretation of the results is in progress, to improve the accuracy. The researches about how reinforcing percentages and the type of reinforcement 
effects on the change of the electrical conductivity of concrete are also in progress. At the present moment, work is underway to assess the effect of nano additives on electrical resistivity changes in reinforced structures using steel and fiberglass reinforcement.

\section{Conclusions}

The researched have shown that the shape of the electrodes and the percentage of nano modifying additives affect the change in the electrical conductivity of concrete. By analyzing these data, it is possible to estimate the change in internal fatigue in the body of a structure in real time. Currently, works are underway to analyze the influence of reinforcement on the change in electrical conductivity and to develop software modules for processing data to determine the magnitude of the fatigue on electrical resistance.

\section{References}

1. 1.GOST 22690-88 Concretes. Determination of strength by mechanical methods of nondestructive testing (State Construction Committee USSR, 1988)

2. D.Y.Snezhkov, S.N. Leonovich, Construction and reconstruction, 2 (58), 152-160 (2015)

3. H. Wiggenhauser, H. Azar,i Infrastruct Syst [Internet], 23(4) (2017)

4. A.V. Ulybin, Civil Engineering Magazine, 4, 10-15 (2011)

5. A.V.Petukhov, M.O. Korovkin, N.A. Eroshkina, Modern scientific research and innovation. № 3 (2017) [Electronic resource]. URL: http://web.snauka.ru/issues/2017/03/79416 (reference date: 11.12.2017).

6. V.R. Kulkarni Special Issue 20, 5, 26-33 (2016)

7. V. Stengel, Insp. of build. and struct.: probl. and ways of their solut. Proceed. of the VI Internat. Scienti. and Pract. Conf., 189-195 (2015)

8. E.V. Moskvin, A.S. Glazyrin, S.V. Gorodilov, A.V. Putov, Proceedings of the ETU ETU, 6, 49-53 (2016)

9. A.V. Demenev, N.L. Pavlov, Sciences of Europe, 6-2 (6), 23-27 (2016)

10. A.V. Rizhenko; V.H. Rizhenko, S.V. Lankin International Research Journal, 8-3 (50), 86-89 (2016)

11. L.A. Urhanova, S.A. Lhasaranov, S.P. Bardakhanov, Building materials, 8, 52-55 (2014)

12. L.Courard, F. Michel, Cement and Concrete Composites,45, 111-116 (2014)

13. I.You, D .Yoo, \& G. Zi, Sensors (Switzerland), 17 (2017)

14. K. Kawaai, I.Ujike \& H.Okuno, ISEC 2017, (2017)

15. A. Asgharzadeh, K. Reichling, M. Raupach, Concrete Solutions, 181-186 (2016) 